\title{
Retrieval Performance and Indexing Differences in ABELL and MLAIB
}

\section{Vince Graziano}

\begin{abstract}
Searches for 117 British authors are compared in the Annual Bibliography of English Language and Literature (ABELL) and the Modern Language Association International Bibliography (MLAIB). Authors are organized by period and genre within the early modern era. The number of records for each author was sub-divided by format, language of publication, and number of unique citations, defined as records retrieved in one database but not the other. Each of the unique records in one database was searched in the other to examine indexing differences. Of the unique items in ABELL, 49.1\% were due to indexing differences, while indexing differences accounted for $35.4 \%$ of the unique records in MLAIB. The indexing differences significantly impacted the retrieval performance of each database.
\end{abstract}

With constant budgetary restraints, escalating serial costs, and the expanding availability of online resources, academic librarians often face difficult decisions regarding the selection of electronic materials. Even the largest of academic libraries with substantial collections budgets must choose among aggregator multidisciplinary databases and competing disciplinary databases, as it is not usually possible to subscribe to all competing offerings. For small and medium-sized academic libraries, decisions may be more difficult. Depending on the discipline, librarians have several choices in each of these categories: electronic bibliographic indexes representing the field of study; specialized databases; databases that represent a wide variety of academic disciplines; fulltext electronic journal collections; statistical resources; audio, video and image databases; encyclopedias, dictionaries and other reference sources; current and historical newspaper archives; and full-text, online primary sources, many of which are expensive, particularly in the humanities.

Many academic libraries subscribe to one or more aggregator multidisciplinary databases, such as EBSCO's Academic Search (Elite, Premier, and Complete), Gale's Expanded Academic ASAP and Academic OneFile, and ProQuest's Research Library, but it is unlikely that many libraries are able to subscribe to all three (for comparisons see Blessinger \& Olle, 2003; Tal, 2006). Among disciplinespecific databases, choices may be more difficult. For example, when selecting a periodical database in the field of business, the choice is generally between ProQuest's ABI/Inform suite of databases and EBSCO’s Business Source (for comparisons see Fagin, 2001; Golderman \& Connolly, 2009). In sociology, the long-established and authoritative index, Sociological Abstracts, created in 1952, received competition from EBSCO's SocINDEX, which was released in 2005 (for comparisons see Todd, 2006; Wheeler, 2006). The criteria for comparison, both quantitative and qualitative, range 
from title lists of journals indexed to the subject and scope of the database. These are just a few examples of the variety of disciplines with rival databases.

Literature librarians and literary researchers have long wondered which bibliography and periodical index is better: the Annual Bibliography of English Language and Literature (hereafter ABELL) or the Modern Language Association International Bibliography (hereafter MLAIB)? Comparisons of the two bibliographies began in the 1960s, with assessments based on the printed volumes. With the arrival of ABELL in electronic format starting in 1997, the need for comparison with MLAIB, which was available in electronic format, became magnified. Reference librarians with access to both databases are often presented with a common question: Which should I use? Usually, students and researchers ask reference librarians to advise them on which database to use for a specific topic. Frequently, the response to such questions is to recommend both databases. For librarians without access to both databases, affordability is obviously an important component in decision-making, but it is not the only one. When confronted by choices regarding MLAIB and ABELL, both literature and non-literature librarians may very well ask if two literature databases are required. This is a fair question. Studies comparing the two resources may offer some answers.

\section{History, Scope and Structure}

Both ABELL and MLAIB have specific histories, scopes, and structures that must be addressed before comparisons are possible. Published by the Modern Humanities Research Association in Great Britain, ABELL began in 1920 as an annual printed volume. International in scope since its inception, ABELL covers American, British, Canadian, Commonwealth, Irish, and Postcolonial literatures and English-language studies. ABELL consists of references to books, periodical articles, book reviews (primarily of secondary works), collections of essays and unpublished doctoral dissertations (until 1999) written in any language. Launched in 1996 on the Chadwyck-Healey platform, Literature Online (LION), a database of more than 350,000 full-text literary works, introduced ABELL in 1997. The first electronic installment of ABELL included records from the 1980-1994 printed volumes, with the full back files from 1920 onward and the current files added in 1998. Some documents published between 1892 and 1919 were indexed retrospectively, and were included in the printed volumes of the 1920s and 1930s. 
From 1920 to 1999, ABELL assigned at least two subject headings to records about literature: subject author and literary period, expressed in adjectival form such as "nineteenth century." A third subject heading, "English Literature," applies to all literatures written in English and is presumably designed to distinguish these records from those about the "English Language." Titles of literary works were not included as subject headings, except for the works of Chaucer and Shakespeare. Following Chadwyck-Healey's acquisition by Bell and Howell (now ProQuest) in 1999, the subject classification for ABELL expanded to include titles of literary works and topical subject headings for records that entered the database from 2000 onward. It should be noted that some documents published before 2000 entered the database after 1999 and therefore reflect the new subject classification. The new subject headings are listed under "additional search terms" on the Chadwyck-Healey platform, the only platform on which ABELL is available.

MLAIB covers modern languages and literatures from Africa, Asia, Australia, New Zealand, Europe and the Americas. It consists of bibliographic references from more than 4,400 journals in the fields of literature, language, linguistics, folklore, and film and dramatic arts from 1926 to the present. MLAIB indexes books, essays in books, dissertations, conference proceedings, and websites. Book reviews are not indexed. Originally titled the American Bibliography, MLAIB was launched in 1926 as a section of the journal Publications of the Modern Language Association (PMLA) and became a separate publication in 1969. Prior to 1956, MLAIB generally (but not exclusively) indexed documents that were written by American scholars, which may preclude comparisons with other serial bibliographies that included international authors, such as ABELL, at least for that time period.

Perhaps the most documented development in the history of MLAIB was the introduction in 1981, probably owing to the birth of the electronic file on DIALOG in 1978, of a new classification and subject indexing system called CIFT, the Contextual Indexing and Faceted Taxonomic access system. Before 1981, the classification system for the literature components was quite basic and included national literature, expressed in adjectival form such as "American Literature;" literary period, displayed as the years of a century such as "1800-1899;" and author names as subjects such as "Dickinson, Emily." Like ABELL, the titles of literary works were not included as subject headings before 1981, except for the works of Chaucer and Shakespeare. CIFT introduced titles and genres of literary works as subject headings for all subject authors. The new system also created a thesaurus 
of controlled vocabulary, which consists of topical terms and names that are regularly added to the thesaurus to reflect the state of current scholarship. The CIFT system introduced descriptor (or subject) subfields, which attempted to apply "contextual" indexing to records. The subfields included genre (discussion of a specific genre as a whole), scholarly approach (feminist, psychoanalytic, ecocritical), literary influence (defined as influence on an author), literary source (influence by an author), literary theme, and performance medium. The subfields were all very welcome additions.

Over the years, MLAIB has featured many enhancements and platform changes. The early CDROM versions covered the records of the printed volumes from 1981 onward. In January 1997 the electronic MLAIB expanded to include records from 1963 to 1980 and in April 2006 the records from 1926 to 1962 were added. Other enhancements included the introduction of name authorities with years of birth and death (though transliterations and some pseudonyms must be searched through the thesaurus), the indexing of electronic journals and monographs without print equivalents, the inclusion of scholarly websites (since April 2007), and the addition of publisherprovided abstracts (since April 2008). Platforms for the CD-ROM versions included Wilson and SilverPlatter. Today, MLAIB is available on EBSCO, Gale, ProQuest, and the Chadwyck-Healey interface via ProQuest's Literature Online, where it can be searched simultaneously with ABELL.

Retrospective conversion of records prior to 1981, however, is uneven. JSTOR records, which begin in 1889 for the journal Publications of the Modern Language Association, reflect the post-1981 classification system and include abstracts, if provided. Most records created prior to 1981 use the old MLAIB classification system. Both ABELL and MLAIB have two classification systems - old and new - which may require complex and separate search queries depending on the time period of the published documents sought.

\section{Literature Review}

Lewis Sawin (1964), then Associate Professor of English at the University of Colorado, envisaged an "integrated bibliography" for English studies that he defined as "one bibliographical compilation containing every item which has ever been listed in any bibliography ever prepared in the subject field, with provision for continuous addition of new items" (p. 7). Two of the major components of Sawin's ambitious proposal were ABELL and MLAIB. He contended that a "rather large number of 
journals" were indexed by one bibliography and not the other, with MLAIB having "by far the larger number." He stated that, in collaboration with Mr. Charles Nilon, his preliminary study of seventeenth-century documents in both bibliographies revealed an "average percentage of duplication of only 21 per cent," far lower than they had expected (pp. 8-9). No data or elaboration accompanied this statement.

Vincent Tollers and Carole Stroud (1973) randomly selected 15 authors in English and American literature and compared the number of entries for each for the publication years 1956, 1961, and 1967. They acknowledged that a single printed annual volume of each bibliography did not include all entries for one specific publication year. This is why they checked each author in each volume of ABELL from 1955 to 1967 and each volume of MLAIB from 1956 to 1969, looking only for entries that were published in the 3 years chosen for study. They examined a total of 622 entries, finding that for the "average author," 77\% of all entries appeared in MLAIB, with 62\% in ABELL. Although their article did not include the number of entries for each author, they concluded that MLAIB was "decidedly superior" in its coverage of English authors, especially the "obscure" ones, while ABELL had better coverage of the "well-known" authors. Indeed, they claimed that their most "significant discovery" was that the researcher "should definitely" consult MLAIB as a first resource to find the "most entries" on English authors (pp. 126-128).

Abigail Loomis (1986) tested the traditional assumption that there is extensive duplication or overlap in the coverage of literary studies in seven serial bibliographies, including ABELL and MLAIB. Citing Sawin and Nilon's conclusion that the average rate of duplication in ABELL and MLAIB was 21\% for seventeenth-century literature, Loomis focused on Charles Dickens scholarship in her study of overlap. Much higher than the percentage reported by Sawin and Nilon, she found that the duplication rate for MLA citations in ABELL was 80\%, while the rate for ABELL references in MLAIB was 71\%. Still, 20\% of ABELL records and 29\% of MLAIB records were unique. She discovered that ABELL had the most number of book records without analytics - which provide contents of books or essay collections - that should or would have included Dickens as a subject heading if the individual chapters or essays had been included as entries. Looking at the printed volumes of ABELL and MLAIB for 1980, she identified a problem with currency in ABELL. Although the 1980 volume of ABELL was published in 1983, there was a time lag of 3 years or more for $66 \%$ of the entries. She concluded that studies of other authors or literary periods were needed, as well 
as research that examined the nature of the duplication in terms of subject, type, and format of materials.

Jost Hindersmann (1997), in his book MLAIB und ABELL, written in German, randomly selected 10 British, 10 American and 10 postcolonial authors. He compiled the number of records as well as the number of unique records for each author. Limiting his study to 1993 publications, he examined the printed volumes of each bibliography for this portion of his comparison. He found that ABELL was stronger in British literature while MLAIB had greater numbers of entries for American and postcolonial literature. He concluded by recommending the use of both bibliographies.

Some reference works, in their descriptions of ABELL and MLAIB, have also compared the two. Citing "current comparisons," Michael Marcuse (1990) stated that ABELL indexes a different set of journals from MLAIB and that both bibliographies should be consulted. James Bracken (1990) examined 28 references to Stephan Crane scholarship - 15 in ABELL and 13 in MLAIB - in the 1984 printed volumes of both bibliographies and discovered that only 3 were identical. Citing studies by Scott Stebelman and Hindersmann, James Harner (2008) stated that "any search of MLAIB must be complemented by a search of ABELL, and vice versa, for each volume of these two resources includes scores of works omitted from the other" (p. 51).

Scott Stebelman (2000) compared 15 topics, consisting of authors and canonical works, and presented the following data for each: total number of records; number of monographs; number of dissertations; number of journal articles; number of foreign-language works; and the number of unique records in each database. He found, somewhat surprisingly, that MLAIB, often criticized for inadequate indexing of monographs, covered book literature better than anticipated, and that ABELL, often praised for its superior coverage of dissertations, retrieved a lower number of dissertation citations. Of the total citations retrieved in ABELL, $31.8 \%$ were unique, while $60.7 \%$ of MLAIB records were unique. Unlike previous studies, Stebelman's work used the electronic versions of ABELL and MLAIB, and he chose a much larger range of publication years, 1980-1996. The sample represented different literary periods and national literatures. He concluded that MLAIB retrieved "significantly more citations" to British, American and postcolonial authors, but that there were enough unique items in each database that "comprehensive literature reviews" 
required the use of both resources (p. 337-38). He stressed the need for more detailed studies of literary periods and genres.

\section{Methodology}

Most of the previous studies were based on the printed volumes and used authors as subject headings. The exception is Stebelman's comparison, which used keyword searches. Despite the contention that the vocabulary of the humanities is "soft" or imprecise compared to the sciences and social sciences, authors as subjects represent fairly precise and consistent search queries, and this subject heading is indexed by both ABELL and MLAIB. Stephen E. Wiberley (1983; 1988; see also Stebelman 1994) argues that some of the vocabulary used by humanists is not as imprecise as had been assumed. Examining terminology in encyclopedias, dictionaries, and periodical indexes in the humanities, he contends that singular proper terms, especially names of people, are precise and predominant in the humanities. However, there are some problems associated with names, such as pseudonyms, transliterated names, or names with titles. For example, ABELL uses Newcastle, Margaret Cavendish, Duchess of, while MLAIB lists her as Cavendish, Margaret, Duchess of Newcastle. For the present study, 117 authors were selected from the Dictionary of Literary Biography (DLB); the authors were divided into periods and genres, also chosen from the DLB. All are British authors, since there is some discrepancy in previous research as to which bibliography had better coverage of this group.

Most of the previous studies were based on one publication year in the printed volumes, while Stebelmen covered a period of 16 years to increase the validity of the statistical analysis (2000). This study selected a 10-year range from 1983 to 1992 for several reasons. Firstly, the literature of the nature of humanities research and the information-seeking behavior of humanists confirms that knowledge is cumulative rather than successive and that retrospective material, whether primary or secondary, is as important as current research (see Stone, 1982; Watson-Boone, 1994; Wiberley \& Jones, 1989). Secondly, citation studies reveal that secondary sources cited by literary scholars pre-date their research, on average, by 20 to 30 years, or longer, depending on the age of the literary topic (Stern, 1983; Watson-Boone, 1994) Thirdly, both ABELL and MLAIB have had some problems concerning currency. Danielle Uchitelle (1998) examined the currency of records in MLAIB from 1986 to 1995 . She discovered that more than $90 \%$ of the records were published 
within 3 years of the item's publication, while each annual volume contained "a few records even older than 9 years prior to publication" (p. 48). Loomis (1986) reported a time lag of 3 or more years for $66 \%$ of the 1980 ABELL entries and 4 years or more for $34 \%$ of the records. For example, the article "Voices of Translation: Poet's Voice and Woman's Voice," published in Pacific Coast Philology in 1993, entered ABELL in 2003; the article "Richler et Londres," published in Etudes Canadiennes/Canadian Studies (France) in 1980 appeared in MLAIB in 1997. For the current study, the period of 1983 to 1992 was selected, with 117 author searches conducted in 2004 and 2005, allowing records to enter the two databases in updates subsequent to 1992. The data was compiled and analyzed from 2005 to 2010.

The early modern period (1500-1660) was selected because author searches in later periods yielded too many results. Each table represents a specific sub-period and genre: results from the searches in Tudor and Elizabethan poetry were entered in Tables 1.1 and 1.2; those from Tudor and Elizabethan drama were recorded in Tables 2.1 and 2.2; Tables 3.1 and 3.2 represented sixteenthcentury prose; Jacobean and Caroline poetry results were logged in Tables 4.1 and 4.2; Jacobean Caroline drama results were listed in Tables 5.1 and 5.2; and Tables 6.1 and 6.2 represented seventeenth-century prose. Some authors were eliminated because they also retrieved too many results; these are Edmund Spenser, Sir Philip Sidney, William Shakespeare, John Milton, and John Donne. Sir Thomas More was excluded because it was difficult to distinguish the many records about him from Shakespeare's work of the same name, both of which are subject headings. Searches in MLAIB were conducted on the now-defunct SilverPlatter platform, while the Literature Online version was used for ABELL. Although the searches were spread out over time, each author was searched in each database, one immediately after the other, and the results printed. MLAIB searches were limited by document type and language, while the ABELL results had to be tabulated manually; for example, the document type "article" in ABELL retrieves both essays in books and journal articles, and there are no limit functions for dissertations and language. Book reviews in ABELL were eliminated. Some edited books were easily retrieved by author as subject searches, such as an edited collection about one author. If the edited book did not include its component chapters or essays in one database, the essays were not counted as separate entries from the other database. If the edited book had citations for its chapter(s) as well as a citation for the book, the latter was eliminated. The number of book citations with limited or no analytics was entered in column C of each table. 
Previous researchers have counted the number of "unique" records on a particular author found in ABELL and MLAIB and others have alluded to materials found in one database but not the other by examining overlap or duplication. However, most of these unique records have not been studied closely. Are such unique records simply not listed in the other database, or does replicating the search not retrieve them? This study reproduces part of Stebelman's comparison by selecting 117 British authors, examining 7,060 records, recording the different formats of citations and tabulating the number of unique records. Each of the unique records in one database was checked in the other database to determine some of the indexing differences. The titles of unique records in one database were searched in the other. Some of these records were indeed found in the other database, but there was no indexing for a particular author. These types of citations are listed in column B of each table.

When a unique record was not found in the database via a title search, then a journal name search limited to publication year(s) was conducted to see if the journal was indexed by the other database. If issues or volumes of journals were not indexed up to gaps of 5 years (an arbitrary number), these are recorded in column A of each table. There were many examples of missed articles, issues and volumes, particularly in ABELL. Examples include Shakespeare Quarterly (1986 missing in ABELL); Explorations in Renaissance Culture (no indexing in MLAIB for 1982 and 1983); Renascence (no indexing in MLAIB for 1992); Explicator (no records in ABELL for 1982 and 1983); SEL: Studies in English Literature 1500-1900 (no records in ABELL for 1989 and 1990); Prose Studies: History, Theory, Criticism (no indexing in ABELL for 1988 and 1989); Philological Quarterly (no entries in ABELL for 1983 and 1984) and Sewanee Review (no indexing in ABELL for 1987 and 1990, and no entries in MLAIB for 1991 and 1992). Some of these are major journals, while others may be selectively indexed for literary content, or in ABELL's case, English literary content. An article that appears in one database, and the journal is indexed by both databases, should also appear in the other database since British authors are well within the scope of both ABELL and MLAIB.

There are several reasons for missing issues or volumes, especially considering that both ABELL and MLAIB are major undertakings. Uchitelle (1998) points out some of the factors for the late indexing of some journals. Among these factors are delays in journal publication, missing issues or 
volumes that must be claimed from the publisher, and difficulty in obtaining some journals. Such factors could easily contribute to whole issues or volumes that are missed. Harner (2003), who became a Field Bibliographer for MLAIB in 1973, criticized the Modern Language Association by stating that problems of coverage in MLAIB may be attributed, at least in part, to "a steady decline in the number of entries contributed by Field Bibliographers" and the "failure of the MLA to increase the number of paid MLAIB staff" (p. 155). The editor of MLAIB, Barbara Chen (2004), in an email to the MLAIB electronic mailing list, which does not have an online archive, offered a reply to Harner's criticism: "We now have a staff of thirty three people who created almost 66,000 records for our 2002 volume. That's a 20\% increase over the records he (Harner) lists for 1995." She added that "We are working diligently to improve our treatment of journals and monographs and have instituted controls to be better able to avoid gaps in coverage." The possibility that some articles, issues or volumes of journals may be missing from either bibliography reinforces the need for the researcher to consult both ABELL and MLAIB.

\section{Results}

Tollers and Stroud stated that ABELL had better coverage of "well-known" English authors, while MLAIB had better coverage overall, particularly of the "obscure" ones, though names were not provided. Hindersmann found that ABELL was stronger in British literature, while Stebelman concluded that MLAIB retrieved "significantly more citations" to British authors. In this study, MLAIB searches yielded the highest number of results for total records, journal articles, books and essays in books, and non-English publications. In aggregate numbers, MLAIB had more citations to books and essays in books, confirming Stebelman's results, though somewhat surprisingly, that the coverage of monographs in MLAIB was better than anticipated. However, the percentages of total records that represented books/essays was 24.8 in MLAIB and 24.2 in ABELL, suggesting that both databases were fairly even in coverage of monographs. While MLAIB retrieved more records for almost each format, the exception is dissertations, as ABELL had greater numbers of dissertations in all periods and genres, excluding sixteenth-century prose. MLAIB includes theses from Dissertations Abstracts International but not Index to Theses in Great Britain and Ireland. ABELL indexed both sources, at least until 1999. 
Except for sixteenth century-prose, the results were consistent by genre and period. The totals for each period/genre were calculated by adding the results for each author-as-subject search; these are listed in Table 7. It should be noted, however, that some records are about more than one author, and these were retrieved more than once by individual author searches. Of the total citations retrieved in ABELL, 27\% were unique, while 43\% of MLAIB records were unique. These results are lower than Stebelman's figures of 31.8 and 60.7\% respective overlap. This may be explained in part by Stebelman's inclusion of American and postcolonial authors in addition to British writers. Another explanation is the sample size; the 117 authors represented a much larger sample than previous research. The 12-year time lag between the final publication year reviewed, and the searches, compared to Stebelman's time lag of 3 years, may also explain the variance in results, allowing for more records to enter each database, which could result in fewer unique records.

The three categories of indexing differences in ABELL account for $49.1 \%$ of the MLAIB unique records, while $35.4 \%$ of ABELL unique records were due to these indexing differences. According to Harner (2003), "comparing the number of hits a search generates [in ABELL and MLAIB] is equally invalid because of the greater level of indexing in $M L A I B$ (p. 51). The indexing system introduced in MLAIB in 1981, holistically, is indeed greater in depth and breadth than ABELL's pre-2000 classification, but authors as subjects are key indexing elements in each database, which validates this type of comparison. Of the 1,713 unique records in MLAIB, 468 were listed in ABELL without indexing for a specific author, while 129 of the 835 unique records in ABELL were found in MLAIB. In terms of percentages, $27.3 \%$ of MLAIB unique citations and 15.5\% of ABELL unique records had different subject indexing in the other database. Based on these numbers, it can be argued that MLAIB had greater level of indexing for subject authors, but the $15.5 \%$ variation is significant. It may be more precise to state that indexing patterns are different, rather than greater or lower.

\section{Conclusion and Further Study}

The $27 \%$ unique records in ABELL and the $43 \%$ unique records in MLAIB indicate that MLAIB should be the first choice for libraries supporting undergraduate literature programs that cover British literature. But for libraries supporting graduate and post-doctoral programs and faculty research, the $27 \%$ unique records in ABELL is substantial enough to warrant the acquisition of both 
databases. Because missing articles, issues, or volumes of journals affect retrieval performance in both ABELL and MLAIB, researchers need to consult both resources and perhaps additional sources as Loomis had suggested in 1986. Missing volumes of journals, along with other matters, such as currency and the new and old classification systems in both ABELL and MLAIB, could be interesting topics for further study, especially from 2000 onwards. The high percentages in the three categories of indexing differences - missing volumes, different subject-author indexing, and lack of analytics for books - not only indicate possible areas for improvement for both ABELL and MLAIB, but also that the serious researcher needs to consult both databases.

The indexing differences substantially impacted the retrieval performance of each database. Comparing databases by the number of journals indexed or by title lists of journals, though essential, is insufficient in terms of criteria for comparison, at least for ABELL and MLAIB. The 49.1\% of MLAIB unique records for ABELL and the 35.4\% of ABELL unique items for MLAIB, in terms of indexing differences, are significant. In other words, ABELL researchers would have retrieved 49.1\% more citations had they used both ABELL and MLAIB, while MLAIB researchers would have retrieved $35.4 \%$ more records by using both databases. When considering competing databases for acquisition, it may be necessary to add indexing differences to the criteria by which databases are compared. Studies comparing other competing databases, with criteria established for specific subject areas, may facilitate the selection process for academic librarians. In terms of ABELL and MLAIB, if an institution cannot afford access to both databases, therefore, weighing the relative indexing strengths of each against the departmental teaching and research specialties, and the level of study offered, emerges as a necessary activity. 


\section{References}

Blessinger, Kelly and Maureen Olle (2003). Comparison of three primary aggregator databases. Serials Librarian 45(1), 53-58.

Bracken, James K. (1990). Reference works in British and American literature (Vol. 1, English and American literature, see Chapter 4, Examples 129 and 130). Englewood, CO: Libraries Unlimited.

Chen, Barbara [email to MLAIB-L@listserv.uiuc.edu] (2004, February 10).

Fagan, Judy Condit (2001). Searching for e-business information in online databases. Behavioral and Social Sciences Sciences Librarian 20(1), 45-53.

Golderman, Gail and Bruce Connelly (2009, January). Getting down to business. Library Journal 134(1), S16-S22.

Harner, James L. (2003). Some suggestions for the future of the MLA International Bibliography. In David William Foster and James R. Kelley (Eds.) Bibliography in literature, folklore, language and linguistics: Essays on the status of the field (pp. 153-60). Jefferson, NC: McFarland.

Harner, James L. (2008). Literary research guide: An annotated listing of reference sources in English literary studies ( $5^{\text {th }}$ ed., see Chapter G, Examples 335 and 340). New York, NY: Modern Language Association.

Hindersmann, Jost (1997). MLAIB und ABELL: Periodische Fachbibliogrphien, CD-ROM- und OnlineDatabanken zur Anglistik (MLAIB and ABELL: Serial bibliographies, CD-ROM and online databases in English studies). Münster: LIT.

Loomis, Abigail A. (1986). Dickens duplications: A study of overlap in serial bibliographies in literature. $R Q 25(3), 348-355$.

Marcuse, Michael J. (1990). A reference guide for English studies (see Chapter L, Example 21). Berkeley, CA: University of California Press.

Sawin, Lewis (1964). The integrated bibliography for English studies: Plan and project. Pennsylvania Library Association Bulletin 19(3), 7-19.

Stebelman, Scott (1994). Vocabulary control and the humanities: A case study of the MLA International Bibliography. Reference Librarian 22(47), 61-78.

Stebelman, Scott (2000). Retrieval performance and citation characteristics of the MLA International Bibliography and the Annual Bibliography for English Language and Literature: A comparative study. Journal of Documentation 56(3), 332-340.

Stern, M. (1983). Characteristics of the literature of literary scholarship. College and Research Libraries, 44(4), 199-209.

Retrieval Performance and Indexing Differences in ABELL and MLAIB 
Stone, Sue (1982). Humanities scholars: Information needs and uses. Journal of Documentation 38(4), 292-313.

Tal, Naama (2006). Which one to choose? A comparison between three aggregators. Knowledge Quest 34(3), 24-29.

Todd, Julia (2006). Choosing databases for sociology: SocINDEX or Sociological Abstracts. Online $30(4), 35-38$.

Tollers, Vincent L. and Carole Stroud (1973). Is the MLA or MHRA better? RQ 13, 126-128.

Uchitelle, Danielle (1998) Currency of coverage in the MLA International Bibliography. Publishing Research Quarterly 14(1), 46-51.

Watson-Boone, Rebecca (1994). The information needs and habits of humanities scholars. RQ 34(2), 203-15.

Wheeler, Kathy (2006). Sociological Abstracts and SocINDEX with full text. Charleston Advisor 8(1), 5-9.

Wiberley, Stephen E. (1983). Subject access in the humanities and the precision of the humanist's vocabulary. Library Quarterly 53(4), 420-33.

Wiberley, Stephen E. (1988). Names in space and time: The indexing vocabulary of the humanities. Library Quarterly 58(1), 1-28.

Wiberley, Stephen E. and William G. Jones (1989). Patterns of information seeking in the humanities. College \& Research Libraries 50(6), 638-45.

Received: June 12, 2012

Accepted: July 15, 2012 
Table 1.1: Tudor and Elizabethan Poetry (1500-1603)

\begin{tabular}{|c|c|c|c|c|c|c|c|c|c|}
\hline \multirow{2}{*}{ Authors } & \multirow{2}{*}{$\begin{array}{l}\text { Journal } \\
\text { Articles }\end{array}$} & \multirow{2}{*}{$\begin{array}{c}\text { Books/ } \\
\text { Essays }\end{array}$} & \multirow[b]{2}{*}{ Diss. } & \multicolumn{2}{|l|}{ Foreign } & \multirow[b]{2}{*}{ Unique } & \multicolumn{3}{|c|}{ Indexing Differences } \\
\hline & & & & Lang. & Total & & A & B & C \\
\hline \multicolumn{10}{|l|}{ Barnes, Barnabe } \\
\hline$A B E L L$ & 4 & 0 & 0 & 0 & 4 & 0 & 0 & 0 & 0 \\
\hline$M L A I B$ & 4 & 0 & 0 & 0 & 4 & 0 & 0 & 0 & 0 \\
\hline \multicolumn{10}{|c|}{ Buchanan, George } \\
\hline$A B E L L$ & 2 & 3 & 1 & 0 & 6 & 3 & 2 & 3 & 8 \\
\hline$M L A I B$ & 11 & 18 & 1 & 4 & 30 & 27 & 0 & 0 & 0 \\
\hline \multicolumn{10}{|l|}{ Daniel, Samuel } \\
\hline$A B E L L$ & 6 & 2 & 3 & 0 & 11 & 3 & 1 & 6 & 2 \\
\hline$M L A I B$ & 12 & 12 & 3 & 0 & 27 & 19 & 0 & 0 & 0 \\
\hline \multicolumn{10}{|l|}{ Douglas, Gawin } \\
\hline$A B E L L$ & 6 & 6 & 4 & 0 & 16 & 7 & 0 & 4 & 1 \\
\hline$M L A I B$ & 8 & 7 & 2 & 1 & 17 & 8 & 0 & 2 & 0 \\
\hline \multicolumn{10}{|l|}{ Davies, Sir John } \\
\hline$A B E L L$ & 5 & 1 & 0 & 0 & 6 & 0 & 1 & 1 & 0 \\
\hline$M L A I B$ & 8 & 1 & 0 & 0 & 9 & 3 & 0 & 0 & 0 \\
\hline \multicolumn{10}{|l|}{ Drayton, Michael } \\
\hline$A B E L L$ & 9 & 4 & 3 & 0 & 16 & 4 & 2 & 4 & 0 \\
\hline$M L A I B$ & 17 & 1 & 4 & 1 & 22 & 10 & 0 & 2 & 0 \\
\hline \multicolumn{10}{|l|}{ Dunbar, William } \\
\hline$A B E L L$ & 27 & 14 & 8 & 1 & 49 & 13 & 1 & 3 & 2 \\
\hline$M L A I B$ & 33 & 17 & 7 & 0 & 57 & 21 & 2 & 3 & 0 \\
\hline \multicolumn{10}{|l|}{ Hawes, Stephen } \\
\hline$A B E L L$ & 6 & 1 & 0 & 0 & 7 & 2 & 0 & 0 & 1 \\
\hline$M L A I B$ & 5 & 1 & 0 & 0 & 6 & 1 & 1 & 0 & 0 \\
\hline \multicolumn{10}{|c|}{$\begin{array}{l}\text { Howard, Henry, Earl of } \\
\text { Surrey }\end{array}$} \\
\hline$A B E L L$ & 8 & 5 & 0 & 1 & 13 & 7 & 1 & 0 & 0 \\
\hline$M L A I B$ & 7 & 2 & 0 & 0 & 9 & 3 & 1 & 0 & 0 \\
\hline
\end{tabular}

A Number of citations not found due to selective indexing of the journal volume and/or issue, or short gaps between indexed years.

B Number of citations listed in database, but no subject indexing for this author.

C Number of book citations with limited or no analytics. 
Table 1.2: Tudor and Elizabethan Poetry (1500-1603)

\begin{tabular}{|c|c|c|c|c|c|c|c|c|c|}
\hline \multirow[b]{2}{*}{ Authors } & \multirow{2}{*}{$\begin{array}{l}\text { Journal } \\
\text { Articles }\end{array}$} & \multirow{2}{*}{$\begin{array}{c}\text { Books/ } \\
\text { Essays }\end{array}$} & \multicolumn{3}{|c|}{ Foreign } & \multirow[b]{2}{*}{ Unique } & \multicolumn{3}{|c|}{ Indexing Differences } \\
\hline & & & Diss. & Lang. & Total & & $\mathbf{A}$ & B & C \\
\hline \multicolumn{10}{|c|}{ Gascoigne, George } \\
\hline$A B E L L$ & 13 & 0 & 2 & 0 & 15 & 3 & 1 & 3 & 0 \\
\hline$M L A I B$ & 14 & 0 & 2 & 0 & 16 & 4 & 1 & 1 & 0 \\
\hline \multicolumn{10}{|c|}{ Greville, Fulke, Baron } \\
\hline \multicolumn{10}{|l|}{ Brooke } \\
\hline$A B E L L$ & 8 & 6 & 6 & 0 & 20 & 8 & 5 & 3 & 0 \\
\hline$M L A I B$ & 17 & 6 & 6 & 1 & 29 & 17 & 0 & 1 & 2 \\
\hline \multicolumn{10}{|c|}{ Lindsay, Sir David } \\
\hline$A B E L L$ & 5 & 9 & 2 & 1 & 16 & 10 & 0 & 0 & 1 \\
\hline$M L A I B$ & 5 & 4 & 1 & 0 & 10 & 4 & 3 & 1 & 0 \\
\hline \multicolumn{10}{|l|}{ Pembroke, Mary } \\
\hline \multicolumn{10}{|c|}{ Herbert, Countess of } \\
\hline$A B E L L$ & 8 & 10 & 1 & 0 & 19 & 2 & 2 & 2 & 3 \\
\hline$M L A I B$ & 14 & 16 & 1 & 0 & 31 & 14 & 1 & 0 & 0 \\
\hline \multicolumn{10}{|l|}{ Skelton, John } \\
\hline$A B E L L$ & 27 & 14 & 6 & 1 & 47 & 9 & 6 & 3 & 0 \\
\hline$M L A I B$ & 34 & 15 & 6 & 3 & 55 & 17 & 2 & 2 & 0 \\
\hline \multicolumn{10}{|c|}{ Southwell, Robert } \\
\hline$A B E L L$ & 5 & 2 & 5 & 1 & 12 & 5 & 1 & 2 & 0 \\
\hline$M L A I B$ & 11 & 3 & 1 & 1 & 15 & 8 & 0 & 0 & 1 \\
\hline \multicolumn{10}{|c|}{ Whitney, Geoffrey } \\
\hline ABELL & 1 & 2 & 0 & 0 & 3 & 2 & 1 & 2 & 0 \\
\hline$M L A I B$ & 5 & 1 & 0 & 0 & 6 & 5 & 0 & 1 & 0 \\
\hline \multicolumn{10}{|l|}{ Whitney, Isabella } \\
\hline$A B E L L$ & 2 & 0 & 1 & 0 & 3 & 0 & 1 & 1 & 0 \\
\hline$M L A I B$ & 4 & 1 & 1 & 0 & 6 & 3 & 0 & 0 & 0 \\
\hline \multicolumn{10}{|c|}{ Wyatt, Sir Thomas } \\
\hline$A B E L L$ & 34 & 14 & 3 & 3 & 51 & 11 & 1 & 3 & 0 \\
\hline$M L A I B$ & 38 & 11 & 3 & 3 & 52 & 12 & 4 & 1 & 0 \\
\hline
\end{tabular}

A Number of citations not found due to selective indexing of the journal volume and/or issue, or short gaps between indexed years.

B Number of citations listed in database, but no subject indexing for this author.

C Number of book citations with limited or no analytics. 
Table 2.1: Tudor and Elizabethan Drama

\begin{tabular}{|c|c|c|c|c|c|c|c|c|c|}
\hline \multirow{2}{*}{ Authors } & \multirow{2}{*}{$\begin{array}{l}\text { Journal } \\
\text { Articles }\end{array}$} & \multirow{2}{*}{$\begin{array}{c}\text { Books/ } \\
\text { Essays }\end{array}$} & \multicolumn{3}{|c|}{ Foreign } & \multirow[b]{2}{*}{ Unique } & \multicolumn{3}{|c|}{ Indexing Differences } \\
\hline & & & Diss. & Lang. & Total & & A & B & C \\
\hline \multicolumn{10}{|l|}{ Day, John } \\
\hline$A B E L L$ & 0 & 2 & 0 & 0 & 2 & 0 & 1 & 2 & 0 \\
\hline$M L A I B$ & 2 & 3 & 0 & 1 & 5 & 3 & 0 & 0 & 0 \\
\hline \multicolumn{10}{|c|}{ Edward(e)s, Richard } \\
\hline$A B E L L$ & 2 & 0 & 0 & 0 & 2 & 0 & 0 & 2 & 0 \\
\hline$M L A I B$ & 3 & 0 & 1 & 0 & 4 & 2 & 0 & 0 & 0 \\
\hline \multicolumn{10}{|l|}{ Garter, Thomas } \\
\hline$A B E L L$ & 4 & 0 & 0 & 0 & 4 & 1 & 1 & 0 & 0 \\
\hline$M L A I B$ & 5 & 0 & 0 & 0 & 5 & 2 & 1 & 0 & 0 \\
\hline \multicolumn{10}{|l|}{ Greene, Robert } \\
\hline ABELL & 22 & 9 & 5 & 2 & 36 & 10 & 5 & 9 & 0 \\
\hline$M L A I B$ & 35 & 12 & 4 & 4 & 51 & 25 & 2 & 4 & 0 \\
\hline \multicolumn{10}{|l|}{ Heywood, John } \\
\hline$A B E L L$ & 4 & 4 & 0 & 0 & 8 & 5 & 2 & 0 & 1 \\
\hline$M L A I B$ & 6 & 2 & 0 & 1 & 8 & 5 & 0 & 2 & 0 \\
\hline \multicolumn{10}{|l|}{ Kyd, Thomas } \\
\hline$A B E L L$ & 31 & 6 & 4 & 1 & 41 & 8 & 3 & 9 & 0 \\
\hline$M L A I B$ & 39 & 16 & 3 & 5 & 58 & 25 & 4 & 1 & 0 \\
\hline \multicolumn{10}{|l|}{ Lodge, Thomas } \\
\hline$A B E L L$ & 6 & 5 & 1 & 2 & 12 & 2 & 1 & 6 & 0 \\
\hline$M L A I B$ & 10 & 7 & 3 & 3 & 20 & 10 & 1 & 0 & 0 \\
\hline \multicolumn{10}{|l|}{ Lyly, John } \\
\hline$A B E L L$ & 20 & 12 & 4 & 1 & 36 & 12 & 2 & 8 & 1 \\
\hline$M L A I B$ & 26 & 12 & 2 & 1 & 40 & 16 & 2 & 2 & 0 \\
\hline \multicolumn{10}{|c|}{ Marlowe, Christopher } \\
\hline$A B E L L$ & 160 & 47 & 31 & 20 & 238 & 70 & 16 & 26 & 6 \\
\hline$M L A I B$ & 208 & 61 & 27 & 26 & 296 & 128 & 11 & 9 & 2 \\
\hline
\end{tabular}

A Number of citations not found due to selective indexing of the journal volume and/or issue, or short gaps between indexed years.

B Number of citations listed in database, but no subject indexing for this author.

C Number of book citations with limited or no analytics. 
Table 2.2: Tudor and Elizabethan Drama

\begin{tabular}{|c|c|c|c|c|c|c|c|c|c|}
\hline \multirow[b]{2}{*}{ Authors } & \multirow{2}{*}{$\begin{array}{l}\text { Journal } \\
\text { Articles }\end{array}$} & \multirow{2}{*}{$\begin{array}{c}\text { Books/ } \\
\text { Essays }\end{array}$} & \multicolumn{3}{|c|}{ Foreign } & & \multicolumn{3}{|c|}{ Indexing Differences } \\
\hline & & & Diss. & Lang. & Total & Unique & A & B & C \\
\hline \multicolumn{10}{|c|}{ Munday, Anthony } \\
\hline$A B E L L$ & 7 & 2 & 0 & 0 & 9 & 5 & 1 & 4 & 3 \\
\hline$M L A I B$ & 9 & 4 & 0 & 0 & 13 & 9 & 0 & 3 & 0 \\
\hline \multicolumn{10}{|l|}{ Nashe, Thomas } \\
\hline$A B E L L$ & 23 & 10 & 9 & 5 & 42 & 11 & 3 & 8 & 1 \\
\hline$M L A I B$ & 29 & 11 & 9 & 4 & 49 & 18 & 4 & 1 & 0 \\
\hline \multicolumn{10}{|l|}{ Peele, George } \\
\hline$A B E L L$ & 10 & 3 & 1 & 2 & 14 & 2 & 1 & 4 & 2 \\
\hline$M L A I B$ & 17 & 8 & 0 & 1 & 25 & 12 & 0 & 0 & 0 \\
\hline \multicolumn{10}{|l|}{ Preston, Thomas } \\
\hline$A B E L L$ & 2 & 0 & 0 & 0 & 2 & 0 & 0 & 1 & 0 \\
\hline$M L A I B$ & 3 & 2 & 0 & 0 & 5 & 3 & 0 & 0 & 0 \\
\hline \multicolumn{10}{|l|}{ Rastell, John } \\
\hline$A B E L L$ & 0 & 1 & 0 & 0 & 1 & 0 & 0 & 2 & 0 \\
\hline$M L A I B$ & 1 & 3 & 0 & 0 & 4 & 3 & 0 & 0 & 0 \\
\hline \multicolumn{10}{|c|}{$\begin{array}{l}\text { Sackville, Thomas and } \\
\text { Norton, Thomas }\end{array}$} \\
\hline$A B E L L$ & 5 & 0 & 1 & 0 & 6 & 0 & 0 & 1 & 0 \\
\hline$M L A I B$ & 7 & 0 & 1 & 0 & 8 & 2 & 0 & 0 & 0 \\
\hline \multicolumn{10}{|l|}{ Udall, Nicholas } \\
\hline$A B E L L$ & 2 & 0 & 0 & 1 & 2 & 1 & 0 & 1 & 0 \\
\hline$M L A I B$ & 5 & 0 & 0 & 2 & 5 & 4 & 1 & 0 & 0 \\
\hline \multicolumn{10}{|c|}{ Whetstone, George } \\
\hline$A B E L L$ & 3 & 1 & 0 & 0 & 4 & 2 & 0 & 2 & 0 \\
\hline$M L A I B$ & 4 & 1 & 0 & 0 & 5 & 3 & 0 & 1 & 0 \\
\hline \multicolumn{10}{|l|}{ Wilson, Thomas } \\
\hline$A B E L L$ & 1 & 1 & 1 & 0 & 3 & 1 & 1 & 2 & 0 \\
\hline$M L A I B$ & 4 & 2 & 1 & 1 & 7 & 5 & 0 & 0 & 0 \\
\hline
\end{tabular}

A Number of citations not found due to selective indexing of the journal volume and/or issue, or short gaps between indexed years.

B Number of citations listed in database, but no subject indexing for this author.

C Number of book citations with limited or no analytics. 
Table 3.1: Sixteenth-Century Prose

\begin{tabular}{|c|c|c|c|c|c|c|c|c|c|}
\hline \multirow{2}{*}{ Authors } & \multirow{2}{*}{$\begin{array}{c}\text { Journal } \\
\text { Articles }\end{array}$} & \multirow{2}{*}{$\begin{array}{c}\text { Books/ } \\
\text { Essays }\end{array}$} & \multicolumn{3}{|c|}{ Foreign } & \multirow[b]{2}{*}{ Unique } & \multicolumn{3}{|c|}{ Indexing Differences } \\
\hline & & & Diss. & Lang. & Total & & $\mathbf{A}$ & B & C \\
\hline \multicolumn{10}{|l|}{ Bale John } \\
\hline$A B E L L$ & 5 & 2 & 0 & 1 & 7 & 4 & 1 & 0 & 1 \\
\hline$M L A I B$ & 4 & 2 & 0 & 1 & 6 & 3 & 2 & 0 & 0 \\
\hline \multicolumn{10}{|l|}{ Camden, William } \\
\hline$A B E L L$ & 5 & 2 & 0 & 0 & 7 & 1 & 0 & 4 & 0 \\
\hline$M L A I B$ & 8 & 3 & 0 & 0 & 11 & 5 & 1 & 0 & 0 \\
\hline \multicolumn{10}{|l|}{ Chettle, Henry } \\
\hline$A B E L L$ & 4 & 0 & 1 & 0 & 5 & 2 & 0 & 2 & 1 \\
\hline$M L A I B$ & 4 & 3 & 1 & 0 & 8 & 5 & 0 & 2 & 0 \\
\hline \multicolumn{10}{|l|}{ Colet, John } \\
\hline$A B E L L$ & 1 & 3 & 1 & 0 & 5 & 3 & 2 & 2 & 1 \\
\hline$M L A I B$ & 5 & 2 & 1 & 0 & 8 & 6 & 0 & 0 & 0 \\
\hline \multicolumn{10}{|l|}{ Foxe, John } \\
\hline$A B E L L$ & 3 & 3 & 1 & 0 & 7 & 3 & 1 & 0 & 1 \\
\hline$M L A I B$ & 8 & 9 & 2 & 0 & 19 & 15 & 0 & 0 & 0 \\
\hline \multicolumn{10}{|l|}{ Golding, Arthur } \\
\hline ABELL & 17 & 1 & 0 & 0 & 18 & 2 & 3 & 3 & 0 \\
\hline$M L A I B$ & 22 & 0 & 0 & 0 & 22 & 6 & 1 & 0 & 0 \\
\hline \multicolumn{10}{|l|}{ Hall, Edward } \\
\hline$A B E L L$ & 1 & 1 & 0 & 1 & 2 & 1 & 0 & 3 & 0 \\
\hline$M L A I B$ & 5 & 2 & 0 & 1 & 7 & 6 & 0 & 1 & 0 \\
\hline \multicolumn{10}{|c|}{ Harington, Sir John } \\
\hline$A B E L L$ & 10 & 3 & 0 & 0 & 13 & 6 & 2 & 1 & 0 \\
\hline$M L A I B$ & 11 & 1 & 0 & 1 & 12 & 5 & 3 & 1 & 0 \\
\hline \multicolumn{10}{|l|}{ Harvey, Gabriel } \\
\hline ABELL & 5 & 1 & 1 & 0 & 7 & 1 & 2 & 5 & 0 \\
\hline$M L A I B$ & 12 & 5 & 1 & 0 & 18 & 12 & 1 & 0 & 0 \\
\hline
\end{tabular}

A Number of citations not found due to selective indexing of the journal volume and/or issue, or short gaps between indexed years.

B Number of citations listed in database, but no subject indexing for this author.

C Number of book citations with limited or no analytics. 
Table 3.2: Sixteenth-Century Prose

\begin{tabular}{|c|c|c|c|c|c|c|c|c|c|}
\hline \multirow[b]{2}{*}{ Authors } & \multirow{2}{*}{$\begin{array}{c}\text { Journal } \\
\text { Articles }\end{array}$} & \multirow{2}{*}{$\begin{array}{c}\text { Books/ } \\
\text { Essays }\end{array}$} & \multicolumn{3}{|c|}{ Foreign } & \multirow[b]{2}{*}{ Unique } & \multicolumn{3}{|c|}{ Indexing Differences } \\
\hline & & & Diss. & Lang. & Total & & $\mathbf{A}$ & B & C \\
\hline \multicolumn{10}{|c|}{ Holinshed, Raphael } \\
\hline$A B E L L$ & 6 & 0 & 0 & 0 & 6 & 1 & 0 & 7 & 1 \\
\hline$M L A I B$ & 12 & 3 & 1 & 1 & 16 & 11 & 0 & 0 & 0 \\
\hline \multicolumn{10}{|l|}{ Hooker, Richard } \\
\hline$A B E L L$ & 2 & 3 & 2 & 1 & 7 & 4 & 1 & 1 & 1 \\
\hline$M L A I B$ & 10 & 6 & 2 & 1 & 18 & 15 & 0 & 0 & 0 \\
\hline \multicolumn{10}{|l|}{ Knox, John } \\
\hline$A B E L L$ & 2 & 1 & 1 & 0 & 4 & 2 & 2 & 2 & 1 \\
\hline$M L A I B$ & 6 & 4 & 0 & 0 & 10 & 8 & 0 & 0 & 0 \\
\hline \multicolumn{10}{|l|}{ Leland, John } \\
\hline$A B E L L$ & 5 & 0 & 0 & 0 & 5 & 1 & 1 & 0 & 0 \\
\hline$M L A I B$ & 8 & 0 & 0 & 0 & 8 & 4 & 1 & 0 & 0 \\
\hline \multicolumn{10}{|c|}{ Puttenham, George } \\
\hline$A B E L L$ & 5 & 3 & 2 & 1 & 10 & 2 & 0 & 5 & 2 \\
\hline$M L A I B$ & 7 & 6 & 2 & 1 & 15 & 7 & 1 & 0 & 0 \\
\hline \multicolumn{10}{|c|}{ Ralegh, Sir Walter } \\
\hline$A B E L L$ & 21 & 5 & 1 & 1 & 27 & 8 & 3 & 8 & 0 \\
\hline$M L A I B$ & 29 & 5 & 1 & 1 & 35 & 16 & 1 & 2 & 0 \\
\hline \multicolumn{10}{|l|}{ Stow, John } \\
\hline$A B E L L$ & 2 & 0 & 0 & 0 & 2 & 0 & 0 & 4 & 1 \\
\hline$M L A I B$ & 5 & 1 & 1 & 0 & 7 & 5 & 0 & 0 & 0 \\
\hline \multicolumn{10}{|l|}{ Tyndale, William } \\
\hline$A B E L L$ & 17 & 2 & 1 & 1 & 20 & 5 & 2 & 0 & 0 \\
\hline$M L A I B$ & 21 & 0 & 2 & 1 & 23 & 8 & 1 & 0 & 0 \\
\hline \multicolumn{10}{|l|}{ Vergil, Polydore } \\
\hline$A B E L L$ & 0 & 0 & 0 & 0 & 0 & 0 & 3 & 1 & 0 \\
\hline$M L A I B$ & 4 & 3 & 0 & 0 & 7 & 7 & 0 & 0 & 0 \\
\hline
\end{tabular}

A Number of citations not found due to selective indexing of the journal volume and/or issue, or short gaps between indexed years.

B Number of citations listed in database, but no subject indexing for this author.

C Number of book citations with limited or no analytics. 
Table 4.1: Jacobean and Caroline Poetry (1603-1660)

\begin{tabular}{|c|c|c|c|c|c|c|c|}
\hline & Journal & Books/ & & Foreign & & & Indexing Differences \\
\hline Authors & Articles & Essays & Diss. & Lang. & Total & Unique & $\begin{array}{lll}\mathbf{A} & \mathbf{B} & \mathbf{C}\end{array}$ \\
\hline
\end{tabular}

Campion, Thomas

ABELL

$M L A I B$

Cavendish, Margaret,

Duchess of Newcastle

$$
\begin{aligned}
& A B E L L \\
& M L A I B
\end{aligned}
$$

Cowley, Abraham

ABELL

$M L A I B$

Carew, Thomas

ABELL

$M L A I B$

Crashaw, Richard

ABELL

$M L A I B$

Davenant, Sir William

ABELL

$M L A I B$

Denham, Sir John

$$
\text { ABELL }
$$

$M L A I B$

Drummond, William of

Hawthornden

$$
\text { ABELL }
$$$$
M L A I B
$$

4

5

5

3

$\begin{array}{lll}4 & 7 & 2\end{array}$

8

6

16

24

$\begin{array}{ll}4 & 2 \\ 6 & 1\end{array}$

12

21

$\begin{array}{ll}3 & 2 \\ 6 & 1\end{array}$

18

18
21

8
10

4
3

$\begin{array}{lll}18 & 2 & 4\end{array}$

11

8

$\begin{array}{rll}7 & 0 & 0 \\ 12 & 0 & 0\end{array}$

12

$\begin{array}{rll}9 & 2 & 0 \\ 10 & 1 & 0\end{array}$

Fletcher, Giles the

Younger

$$
\text { ABELL }
$$

$M L A I B$

Fletcher, Phineas

ABELL

$M L A I B$

Herbert, George

ABELL

$M L A I B$

Herrick, Robert

$A B E L L$

$M L A I B$

King, Henry

$A B E L L$

$M L A I B$

$\begin{array}{lllllllll}2 & 0 & 1 & 0 & 3 & 0 & 0 & 0 & 1 \\ 2 & 2 & 1 & 0 & 5 & 2 & 0 & 0 & 0\end{array}$

$\begin{array}{lllllllll}4 & 0 & 2 & 0 & 6 & 0 & 0 & 0 & 0 \\ 5 & 0 & 2 & 0 & 7 & 1 & 0 & 0 & 0\end{array}$

$\begin{array}{rrrrrrrrr}160 & 41 & 50 & 4 & 251 & 38 & 13 & 15 & 3 \\ 212 & 43 & 43 & 11 & 298 & 85 & 10 & 4 & 0\end{array}$

$\begin{array}{rrrrrrrrr}20 & 7 & 3 & 3 & 30 & 5 & 14 & 1 & 0 \\ 45 & 6 & 2 & 10 & 53 & 29 & 2 & 0 & 0\end{array}$

$\begin{array}{lllllllll}2 & 2 & 0 & 0 & 4 & 3 & 1 & 1 & 2 \\ 3 & 4 & 0 & 0 & 7 & 6 & 0 & 0 & 0\end{array}$

A Number of citations not found due to selective indexing of the journal volume and/or issue, or short gaps between indexed years.

B Number of citations listed in database, but no subject indexing for this author.

C Number of book citations with limited or no analytics.

Retrieval Performance and Indexing Differences in ABELL and MLAIB

Vince Graziano - August 2012 
Table 4.2: Jacobean and Caroline Poetry (1603-1660)

\begin{tabular}{|c|c|c|c|c|c|c|c|c|c|}
\hline \multirow[b]{2}{*}{ Authors } & \multirow{2}{*}{$\begin{array}{l}\text { Journal } \\
\text { Articles }\end{array}$} & \multirow{2}{*}{$\begin{array}{c}\text { Books/ } \\
\text { Essays }\end{array}$} & \multirow{2}{*}{\multicolumn{2}{|c|}{$\begin{array}{cr} & \text { Foreign } \\
\text { Diss } & \text { Lang }\end{array}$}} & \multirow[b]{2}{*}{ Total } & \multirow[b]{2}{*}{ Unique } & \multicolumn{3}{|c|}{ Indexing Differences } \\
\hline & & & & & & & A & B & C \\
\hline \multicolumn{10}{|l|}{ Lanyer, Aemilia } \\
\hline$A B E L L$ & 3 & 2 & 1 & 0 & 6 & 1 & 0 & 0 & 0 \\
\hline$M L A I B$ & 4 & 2 & 0 & 0 & 6 & 1 & 0 & 1 & 0 \\
\hline \multicolumn{10}{|l|}{ Lovelace, Richard } \\
\hline$A B E L L$ & 2 & 3 & 1 & 0 & 6 & 2 & 1 & 3 & 0 \\
\hline$M L A I B$ & 9 & 1 & 1 & 0 & 11 & 7 & 0 & 0 & 0 \\
\hline \multicolumn{10}{|l|}{ Marvell, Andrew } \\
\hline$A B E L L$ & 91 & 29 & 16 & 3 & 136 & 35 & 11 & 15 & 3 \\
\hline$M L A I B$ & 113 & 34 & 14 & 8 & 161 & 60 & 7 & 6 & 0 \\
\hline \multicolumn{10}{|c|}{ Philips, Katherine } \\
\hline$A B E L L$ & 16 & 3 & 3 & 0 & 22 & 5 & 1 & 1 & 2 \\
\hline$M L A I B$ & 16 & 6 & 3 & 1 & 25 & 8 & 3 & 0 & 0 \\
\hline \multicolumn{10}{|l|}{ Quarles, Francis } \\
\hline$A B E L L$ & 2 & 3 & 0 & 0 & 5 & 2 & 2 & 3 & 0 \\
\hline$M L A I B$ & 10 & 3 & 0 & 0 & 13 & 10 & 0 & 0 & 0 \\
\hline \multicolumn{10}{|l|}{ Sandys, George } \\
\hline$A B E L L$ & 1 & 2 & 2 & 0 & 5 & 3 & 0 & 0 & 0 \\
\hline$M L A I B$ & 2 & 0 & 1 & 0 & 3 & 1 & 0 & 1 & 1 \\
\hline \multicolumn{10}{|l|}{ Speght, Rachel } \\
\hline$A B E L L$ & 2 & 0 & 1 & 0 & 3 & 2 & 1 & 2 & 0 \\
\hline$M L A I B$ & 2 & 2 & 0 & 0 & 4 & 3 & 0 & 1 & 0 \\
\hline \multicolumn{10}{|l|}{ Suckling, Sir John } \\
\hline ABELL & 4 & 0 & 0 & 0 & 4 & 0 & 0 & 0 & 0 \\
\hline$M L A I B$ & 5 & 0 & 0 & 0 & 5 & 1 & 0 & 0 & 0 \\
\hline \multicolumn{10}{|c|}{ Traherne, Thomas } \\
\hline$A B E L L$ & 23 & 8 & 8 & 2 & 39 & 17 & 0 & 1 & 0 \\
\hline$M L A I B$ & 20 & 5 & 5 & 2 & 30 & 8 & 3 & 1 & 0 \\
\hline \multicolumn{10}{|l|}{ Vaughan, Henry } \\
\hline$A B E L L$ & 42 & 10 & 7 & 6 & 59 & 16 & 2 & 2 & 1 \\
\hline$M L A I B$ & 51 & 13 & 4 & 12 & 68 & 25 & 2 & 2 & 0 \\
\hline \multicolumn{10}{|l|}{ Waller, Edmund } \\
\hline$A B E L L$ & 4 & 1 & 1 & 0 & 6 & 3 & 0 & 0 & 0 \\
\hline$M L A I B$ & 3 & 1 & 0 & 0 & 4 & 1 & 0 & 2 & 0 \\
\hline \multicolumn{10}{|l|}{ Wither, George } \\
\hline$A B E L L$ & 0 & 1 & 1 & 0 & 2 & 1 & 1 & 1 & 0 \\
\hline$M L A I B$ & 2 & 0 & 1 & 0 & 3 & 2 & 0 & 0 & 0 \\
\hline \multicolumn{10}{|c|}{ Wroth, Lady Mary } \\
\hline$A B E L L$ & 8 & 11 & 3 & 0 & 22 & 4 & 4 & 2 & 2 \\
\hline$M L A I B$ & 11 & 13 & 2 & 0 & 26 & 8 & 0 & 0 & 0 \\
\hline
\end{tabular}

\footnotetext{
A Number of citations not found due to selective indexing of the journal volume and/or issue, or short gaps between indexed years.

B Number of citations listed in database, but no subject indexing for this author.

C Number of book citations with limited or no analytics.
} 
Table 5.1: Jacobean and Caroline Drama (1603-1660)

\begin{tabular}{lrrrrrrrr}
\hline $\begin{array}{c}\text { Journal } \\
\text { Articles }\end{array}$ & $\begin{array}{r}\text { Books/ } \\
\text { Essays }\end{array}$ & Diss. & $\begin{array}{r}\text { Foreign } \\
\text { Lang. }\end{array}$ & Total & Unique & Indexing Differences \\
Authors & & & & & & & & \\
B
\end{tabular}

A Number of citations not found due to selective indexing of the journal volume and/or issue, or short gaps between indexed years.

B Number of citations listed in database, but no subject indexing for this author.

C Number of book citations with limited or no analytics. 
Table 5.2: Jacobean and Caroline Drama (1603-1660)

\begin{tabular}{|c|c|c|c|c|c|c|c|c|c|}
\hline \multirow[b]{2}{*}{ Authors } & \multirow{2}{*}{$\begin{array}{l}\text { Journal } \\
\text { Articles }\end{array}$} & \multirow{2}{*}{$\begin{array}{c}\text { Books/ } \\
\text { Essays }\end{array}$} & \multirow[b]{2}{*}{ Diss. } & \multicolumn{2}{|l|}{ Foreign } & \multirow[b]{2}{*}{ Unique } & \multicolumn{3}{|c|}{ Indexing Differences } \\
\hline & & & & Lang. & Total & & $\mathbf{A}$ & B & C \\
\hline \multicolumn{10}{|l|}{ Marston, John } \\
\hline$A B E L L$ & 28 & 11 & 3 & 3 & 42 & 12 & 2 & 13 & 1 \\
\hline$M L A I B$ & 34 & 19 & 6 & 5 & 59 & 29 & 3 & 3 & 1 \\
\hline \multicolumn{10}{|l|}{ Massinger, Philip } \\
\hline$A B E L L$ & 20 & 17 & 5 & 2 & 42 & 12 & 1 & 6 & 2 \\
\hline$M L A I B$ & 17 & 20 & 2 & 2 & 39 & 9 & 3 & 2 & 0 \\
\hline \multicolumn{10}{|c|}{ Middleton, Thomas } \\
\hline$A B E L L$ & 107 & 28 & 19 & 5 & 154 & 29 & 11 & 12 & 2 \\
\hline$M L A I B$ & 125 & 41 & 14 & 14 & 180 & 55 & 4 & 8 & 0 \\
\hline \multicolumn{10}{|c|}{ Randolph, Thomas } \\
\hline$A B E L L$ & 3 & 1 & 0 & 0 & 4 & 0 & 0 & 0 & 0 \\
\hline$M L A I B$ & 3 & 1 & 0 & 0 & 4 & 0 & 0 & 0 & 0 \\
\hline \multicolumn{10}{|l|}{ Rowley, William } \\
\hline$A B E L L$ & 33 & 9 & 2 & 2 & 44 & 15 & 1 & 12 & 1 \\
\hline$M L A I B$ & 41 & 12 & 0 & 6 & 53 & 24 & 5 & 1 & 0 \\
\hline \multicolumn{10}{|l|}{ Shirley, James } \\
\hline$A B E L L$ & 13 & 9 & 3 & 0 & 25 & 11 & 0 & 2 & 0 \\
\hline MLAIB & 17 & 3 & 1 & 0 & 21 & 7 & 1 & 2 & 0 \\
\hline \multicolumn{10}{|l|}{ Tourneur, Cyril } \\
\hline$A B E L L$ & 14 & 11 & 0 & 3 & 25 & 6 & 2 & 6 & 1 \\
\hline$M L A I B$ & 24 & 10 & 0 & 6 & 34 & 15 & 0 & 0 & 0 \\
\hline \multicolumn{10}{|l|}{ Webster, John } \\
\hline$A B E L L$ & 53 & 28 & 14 & 9 & 95 & 30 & 6 & 8 & 4 \\
\hline$M L A I B$ & 67 & 40 & 10 & 22 & 117 & 52 & 9 & 3 & 1 \\
\hline
\end{tabular}

A Number of citations not found due to selective indexing of the journal volume and/or issue, or short gaps between indexed years.

B Number of citations listed in database, but no subject indexing for this author.

C Number of book citations with limited or no analytics. 
Table 6.1: Seventeenth-Century Prose

\begin{tabular}{|c|c|c|c|c|c|c|c|c|c|}
\hline \multirow[b]{2}{*}{ Authors } & \multirow{2}{*}{$\begin{array}{l}\text { Journal } \\
\text { Articles }\end{array}$} & \multirow{2}{*}{$\begin{array}{c}\text { Books/ } \\
\text { Essays }\end{array}$} & \multicolumn{3}{|c|}{ Foreign } & \multirow[b]{2}{*}{ Unique } & \multicolumn{3}{|c|}{ Indexing Differences } \\
\hline & & & Diss. & Lang. & Total & & $\mathbf{A}$ & B & C \\
\hline \multicolumn{10}{|c|}{ Andrewes, Lancelot } \\
\hline$A B E L L$ & 6 & 2 & 2 & 1 & 10 & 4 & 1 & 0 & 1 \\
\hline$M L A I B$ & 8 & 5 & 2 & 0 & 15 & 9 & 0 & 1 & 0 \\
\hline \multicolumn{10}{|l|}{ Bacon, Francis } \\
\hline$A B E L L$ & 54 & 21 & 19 & 9 & 94 & 42 & 16 & 16 & 3 \\
\hline$M L A I B$ & 86 & 40 & 11 & 21 & 137 & 85 & 11 & 2 & 0 \\
\hline \multicolumn{10}{|c|}{ Browne, Sir Thomas } \\
\hline$A B E L L$ & 27 & 2 & 11 & 2 & 40 & 9 & 4 & 8 & 1 \\
\hline$M L A I B$ & 39 & 5 & 9 & 6 & 53 & 22 & 1 & 3 & 0 \\
\hline \multicolumn{10}{|l|}{ Burton, Robert } \\
\hline$A B E L L$ & 14 & 10 & 10 & 0 & 33 & 7 & 3 & 5 & 3 \\
\hline$M L A I B$ & 22 & 12 & 10 & 2 & 44 & 18 & 0 & 2 & 0 \\
\hline \multicolumn{10}{|c|}{ Clifford, Lady Anne } \\
\hline$A B E L L$ & 2 & 1 & 0 & 0 & 3 & 1 & 0 & 1 & 0 \\
\hline MLAIB & 2 & 0 & 1 & 0 & 3 & 1 & 0 & 0 & 0 \\
\hline \multicolumn{10}{|c|}{$\begin{array}{l}\text { Cornwallis, Sir William } \\
\text { (the Younger) }\end{array}$} \\
\hline$A B E L L$ & 1 & 0 & 0 & 0 & 1 & 0 & 0 & 0 & 0 \\
\hline$M L A I B$ & 1 & 1 & 0 & 0 & 2 & 1 & 0 & 0 & 0 \\
\hline \multicolumn{10}{|l|}{ Coryate, Thomas } \\
\hline$A B E L L$ & 2 & 0 & 0 & 0 & 2 & 1 & 0 & 0 & 0 \\
\hline MLAIB & 2 & 1 & 0 & 0 & 3 & 2 & 0 & 0 & 0 \\
\hline \multicolumn{10}{|l|}{ Evelyn, John } \\
\hline$A B E L L$ & 8 & 5 & 0 & 0 & 13 & 4 & 0 & 0 & 0 \\
\hline$M L A I B$ & 7 & 4 & 0 & 0 & 11 & 1 & 0 & 1 & 0 \\
\hline \multicolumn{10}{|l|}{ Felltham, Owen } \\
\hline$A B E L L$ & 5 & 0 & 0 & 0 & 5 & 1 & 0 & 1 & 0 \\
\hline$M L A I B$ & 5 & 0 & 0 & 0 & 5 & 1 & 0 & 1 & 0 \\
\hline \multicolumn{10}{|c|}{ Filmer, Sir Robert } \\
\hline$A B E L L$ & 1 & 0 & 0 & 0 & 1 & 0 & 0 & 0 & 0 \\
\hline MLAIB & 2 & 0 & 0 & 0 & 2 & 1 & 0 & 0 & 0 \\
\hline
\end{tabular}

A Number of citations not found due to selective indexing of the journal volume and/or issue, or short gaps between indexed years.

B Number of citations listed in database, but no subject indexing for this author.

C Number of book citations with limited or no analytics. 
Table 7: Totals

\begin{tabular}{|c|c|c|c|c|c|c|c|c|c|}
\hline \multirow[b]{2}{*}{ Periods and Genres } & \multirow{2}{*}{$\begin{array}{l}\text { Journal } \\
\text { Articles }\end{array}$} & \multirow{2}{*}{$\begin{array}{c}\text { Books/ } \\
\text { Essays }\end{array}$} & \multirow[b]{2}{*}{ Diss. } & \multirow{2}{*}{$\begin{array}{c}\text { Foreign } \\
\text { Lang. }\end{array}$} & \multirow[b]{2}{*}{ Total } & \multirow[b]{2}{*}{ Unique } & \multicolumn{3}{|c|}{ Indexing Differences } \\
\hline & & & & & & & $\mathbf{A}$ & B & $\mathbf{C}$ \\
\hline \multicolumn{10}{|l|}{ Tudor and Elizabethan } \\
\hline \multicolumn{10}{|l|}{ Poetry } \\
\hline$A B E L L$ & 176 & 93 & 45 & 8 & 314 & 89 & 26 & 40 & 18 \\
\hline$M L A I B$ & 247 & 116 & 38 & 14 & 401 & 176 & 15 & 14 & 3 \\
\hline \multicolumn{10}{|l|}{ Tudor and Elizabethan } \\
\hline \multicolumn{10}{|l|}{ Drama } \\
\hline$A B E L L$ & 302 & 103 & 57 & 34 & 462 & 130 & 37 & 87 & 16 \\
\hline$M L A I B$ & 413 & 144 & 51 & 49 & 608 & 275 & 27 & 24 & 2 \\
\hline \multicolumn{10}{|c|}{ Sixteenth-Century Prose } \\
\hline$A B E L L$ & 111 & 30 & 11 & 6 & 152 & 46 & 23 & 48 & 10 \\
\hline$M L A I B$ & 181 & 55 & 14 & 8 & 250 & 144 & 12 & 6 & 0 \\
\hline \multicolumn{10}{|l|}{ Jacobean and Caroline } \\
\hline \multicolumn{10}{|l|}{ Poetry } \\
\hline$A B E L L$ & 474 & 154 & 116 & 21 & 744 & 180 & 67 & 62 & 22 \\
\hline$M L A I B$ & 627 & 175 & 88 & 52 & 890 & 326 & 32 & 22 & 2 \\
\hline \multicolumn{10}{|l|}{ Jacobean and Caroline } \\
\hline \multicolumn{10}{|l|}{ Drama } \\
\hline$A B E L L$ & 664 & 297 & 134 & 51 & 1095 & 260 & 74 & 154 & 30 \\
\hline$M L A I B$ & 850 & 361 & 112 & 109 & 1323 & 487 & 47 & 45 & 7 \\
\hline \multicolumn{10}{|l|}{ Seventeenth-Century } \\
\hline \multicolumn{10}{|l|}{ Prose } \\
\hline$A B E L L$ & 189 & 71 & 64 & 36 & 323 & 130 & 34 & 77 & 17 \\
\hline$M L A I B$ & 311 & 135 & 52 & 68 & 498 & 305 & 19 & 18 & 1 \\
\hline \multicolumn{10}{|l|}{ TOTALS } \\
\hline$A B E L L$ & 1916 & 748 & 427 & 156 & 3090 & 835 & 261 & 468 & 113 \\
\hline$M L A I B$ & 2629 & 986 & 355 & 300 & 3970 & 1713 & 152 & 129 & 15 \\
\hline
\end{tabular}

A Number of citations not found due to selective indexing of the journal volume and/or issue, or short gaps between indexed years.

B Number of citations listed in database, but no subject indexing for this author.

C Number of book citations with limited or no analytics. 